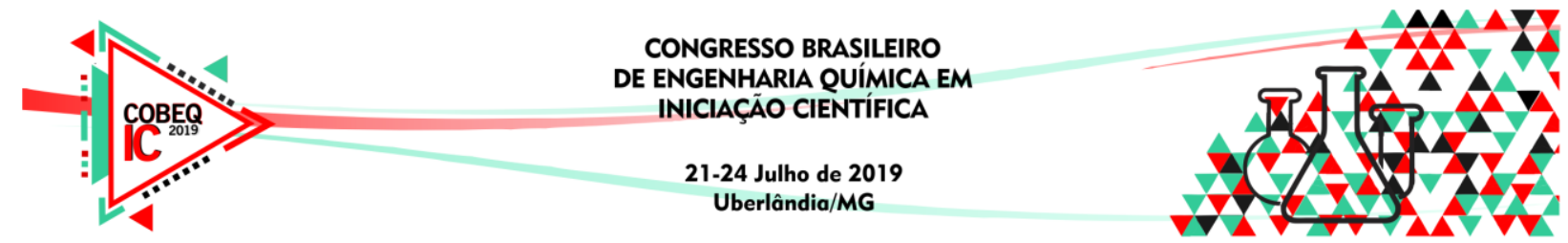

\title{
ESTUDOS DA PRODUÇÃO DE ETANOL ANIDRO POR DESTILAÇÃO AZEOTRÓPICA, EXTRATIVA E ADSORÇÃO
}

\author{
T. S. NUNES ${ }^{1}$, J. R. D. FINZER ${ }^{1}$ \\ ${ }^{1}$ Universidade de Uberaba, Departamento de Engenharia Química \\ E-mail para contato: thiago.engquimica@ hotmail.com
}

\begin{abstract}
RESUMO - O álcool hidratado, produto final das etapas de destilação e retificação, resulta em um teor alcoólico da ordem de até $96^{\circ} \mathrm{GL}$. Essa limitação ocorre devido à formação de uma mistura azeotrópica. $\mathrm{O}$ álcool hidratado pode passar por um dos três processos de desidratação que são: azeotrópica, extrativa e adsorção. O objetivo geral deste trabalho é descrever a produção de etanol hidratado e anidro usando ciclohexano, monoetilenoglicol e peneira molecular. Comparam-se os resultados do etanol hidratado e do etanol anidro por peneira molecular obtido em uma indústria sucroalcooleira com os exigidos em normas da ABNT. O etanol hidratado apesentou densidade de $809,7 \mathrm{~kg} / \mathrm{m} 3$; e o etanol anidro $791 \mathrm{~kg} / \mathrm{m}^{3}$. O INPM do etanol hidratado e anidro foram, respectivamente: 93,0\% e 99,4\%. Todos os outros parâmetros atenderam a normalização da ABNT.
\end{abstract}

\section{INTRODUÇÃO}

Industrialmente, o etanol é obtido na forma de uma solução aquosa diluída, e quando se deseja o álcool anidro é necessário o emprego de uma técnica de separação adequada para que praticamente toda água seja removida da mistura. O etanol é obtido por via destilatória, sintética ou fermentativa (SOLOMONS; FRYHLE, 2001). A via fermentativa é a mais utilizada no mundo e o Brasil domina essa tecnologia, sendo o setor sucroalcooleiro do país um dos mais competitivos, com baixos custos de produção. A partir do ano 2012 o Brasil se posicionou como o segundo maior produtor mundial de etanol (PEREIRA et al., 2012).

Álcool hidratado: aquele comum que é vendido nos postos de combustível, também presente em algumas indústrias, como a farmacêutica, de cosméticos e de produtos de limpeza. Álcool anidro: tem uma pureza alcoólica elevada, e é utilizado no preparo de combustíveis, sendo misturado com a gasolina, para, além de reduzir custos, aumentar a octanagem e reduzir a emissão de poluentes. É empregado, também, na fabricação de polietileno, éter, acetona, na produção de fibras sintéticas, solventes, plastificantes e vernizes.

\section{DESENVOLVIMENTO}

A destilação é uma operação unitária de separação que se baseia nas diferenças de volatilidade dos componentes de uma mistura líquida a serem separados A destilaria é constituída por uma série de colunas de destilação, ver a Figura 2. 


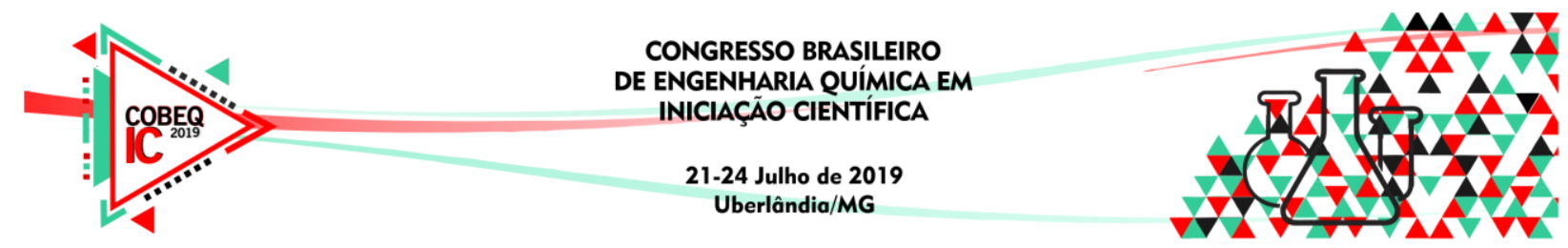

Figura 1: Fluxograma da destilação de etanol.

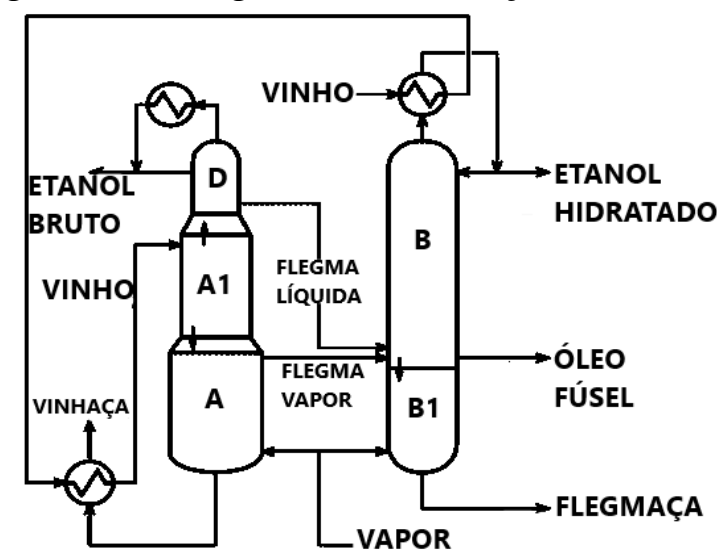

\section{OBJETIVOS}

O objetivo geral deste trabalho é descrever a produção de etanol hidratado e a produção de etanol anidro pelos processos com ciclohexano, monoetilenoglicol e peneira molecular, comparando os resultados de uma indústria sucroalcooleira com os exigidos por norma da ABNT.

\section{METODOLOGIA}

No estudo atual são utilizados dados obtidos de processo industrial de fabricação de etanol, efetuando discussão sobre o desempenho do processo. $\mathrm{O}$ vinho proveniente da fermentação, ver a Figura 1, possui em sua composição, $7^{\circ}$ a $10^{\circ} \mathrm{GL}$ de etanol, além de outros componentes de natureza líquida, sólida e gasosa. A água na mistura possui teores de $89 \%$ a 93\%, e glicerol, álcoois homólogos superiores, furfural, aldeído acético, ácidos succínico e acético em quantidades bem menores.

A destilação é processada em três colunas superpostas: A, A1 e D. Nestas colunas, o etanol é concentrado (inicialmente com $7^{\circ}$ a $10^{\circ} \mathrm{GL}$ ) e sai como flegma (vapores com $40^{\circ}$ a $50^{\circ} \mathrm{GL}$ ). $\mathrm{O}$ tronco de destilação, no topo, elimina ésteres e aldeídos. $\mathrm{O}$ vinho é alimentado no topo da coluna A1, sendo a flegma retirado no fundo da bandeja A16 e enviada à coluna B. Os voláteis são concentrados na coluna $\mathrm{D}$, e uma fração em fase líquida (90\% a 95\% GL) retorna ao topo da coluna $\mathrm{D}$ e a outra é retirada como álcool de $2^{\mathrm{a}}$, com graduação de aproximadamente $92^{\circ} \mathrm{GL}$. O produto de fundo é a vinhaça. O aquecimento da segunda coluna (coluna B), após as colunas superpostas, é realizado pela injeção de vapor (escape ou vegetal) no fundo dessa coluna, ou indiretamente através de um trocador de calor-evaporador.

A finalidade da coluna B é concentrar a flegma a $96^{\circ} \mathrm{GL}$. A mistura hidroalcoólica forma um composto azeotrópico quando atinge a concentração de $96^{\circ} \mathrm{GL}$. Nas destilarias 


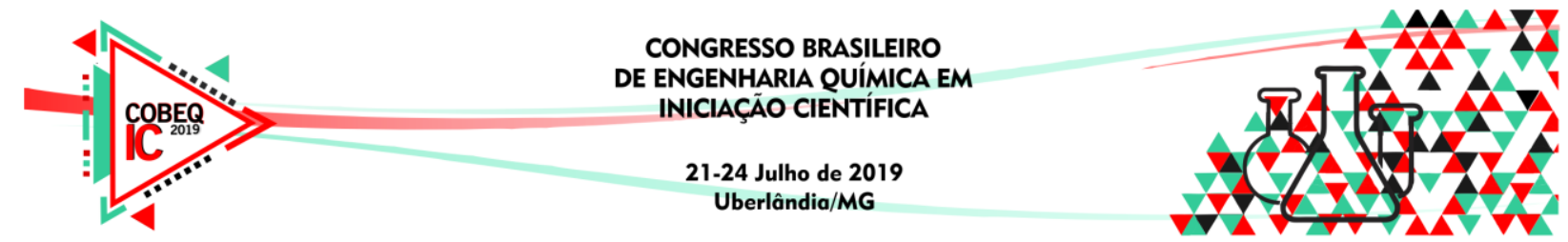

utiliza-se o monoetilenoglicol, ciclohexano ou peneira molecular para promover a desidratação. Os voláteis retirados no topo da segunda coluna B são condensados e uma fração é reciclada e outra retirada como álcool hidratado. Do fundo da coluna é retirada uma solução aquosa chamada flegmaça e que pode ser reciclada no processo ou eliminada. Os álcoois homólogos superiores "óleo fúsel", são retirados de bandejas próximas à entrada da flegma. O álcool hidratado pode ser comercializado ou ser desidratado.

\subsection{Destilação azeotrópica, utilizando ciclohexano}

Este processo utiliza uma coluna de desidratação, sendo o ciclohexano alimentado no topo da coluna $\mathrm{C}$ e o álcool a ser desidratado alimentado a um terço abaixo do topo da coluna $\mathrm{C}$, ver a Figura 2. O ciclohexano tem a característica de formar com o álcool e a água uma mistura ternária (azeótropo) com um ponto de ebulição de $63^{\circ} \mathrm{C}$. Este menor ponto de ebulição da mistura em relação ao do álcool $\left(78^{\circ} \mathrm{C}\right)$, faz com que a água seja retirada no topo da coluna. Por condensação, esta mistura azeotrópica irá se separar em duas fases, a fase inferior, mais rica em água, enviada para outra coluna onde ocorre a recuperação do ciclohexano. O álcool anidro, com um teor alcóolico em torno de 99,3\% p/p, é retirado na parte inferior da coluna de desidratação, de onde é condensado e armazenado.

Figura 2: Configuração industrial de desidratação do etanol por destilação azeotrópica com ciclohexano.

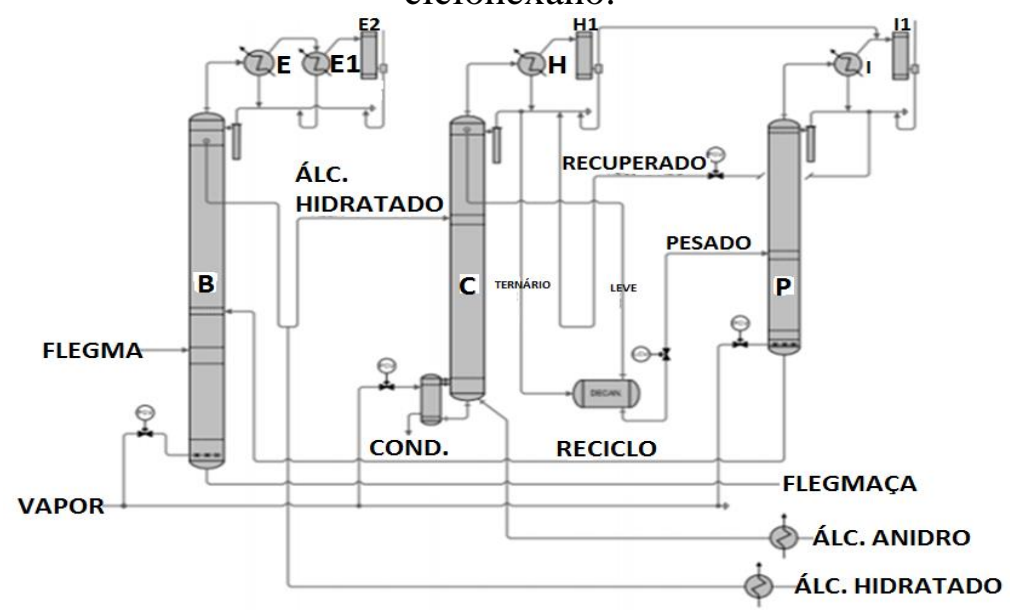

\subsection{Destilação extrativa, utilizando monoetilenoglicol}

Utiliza-se uma coluna de desidratação, onde o monoetilenoglicol (MEG) é alimentado no topo desta coluna e o álcool a ser desidratado também a um terço abaixo do topo da coluna. Inversamente ao processo do ciclohexano, o MEG absorve e arrasta a água para o fundo da coluna e os vapores de álcool anidro saem pelo topo da coluna, ver a Figura 3. A mistura contendo água, MEG e uma pequena quantidade de álcool, é enviada para uma coluna de recuperação do MEG, o qual retorna ao processo de desidratação. 


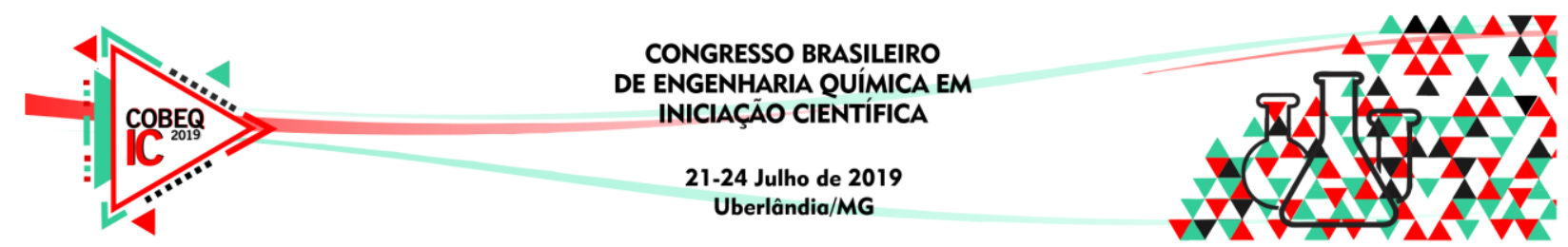

Figura 3: Desidratação do etanol por destilação extrativa com monoetilenoglicol.

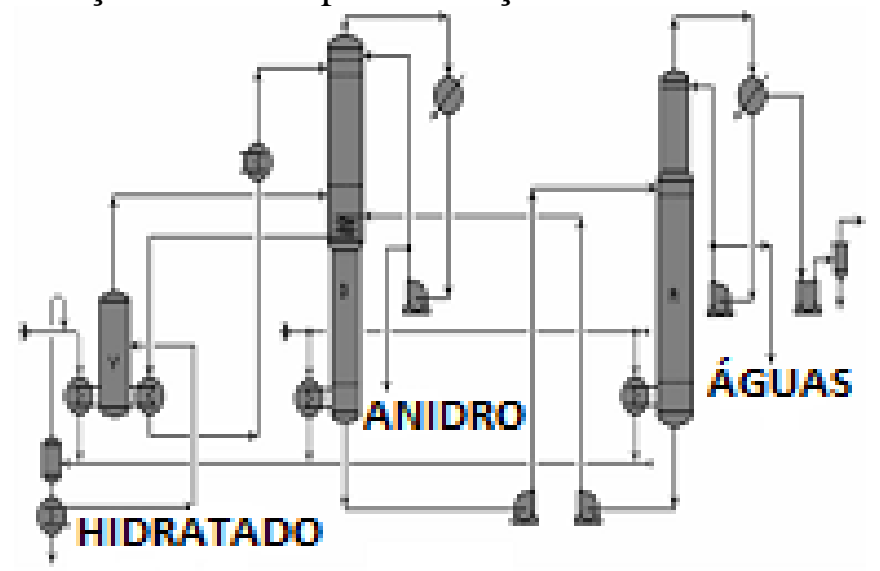

\subsection{Desidratação por adsorção, utilizando peneira molecular}

A zeólita sintética do tipo $3 \AA$ é usada para desidratar o etanol, porque os poros são de diâmetro $3 \AA$ enquanto as moléculas de água são de $2.8 \AA$ e as moléculas de etanol são de $4.4 \AA$ (MARQUINI, 2019). Portanto as moléculas de água são fortemente atraídas para dentro dos poros. A etapa de desidratação não pode ser contínua, necessitando a fase de regeneração da zeólita, ver a Figura 4. Para permitir um processo contínuo dois ou mais leitos dissecantes são previstos. Quando a resina do adsorvedor estiver saturada, a corrente gasosa etanol-água é desviado ao outro adsorvedor. Os ciclos de desidratação e de regeneração se alternam e o processo é controlado automaticamente por sistema supervisório.

Figura 4: Configuração de desidratação do etanol por peneiras moleculares.

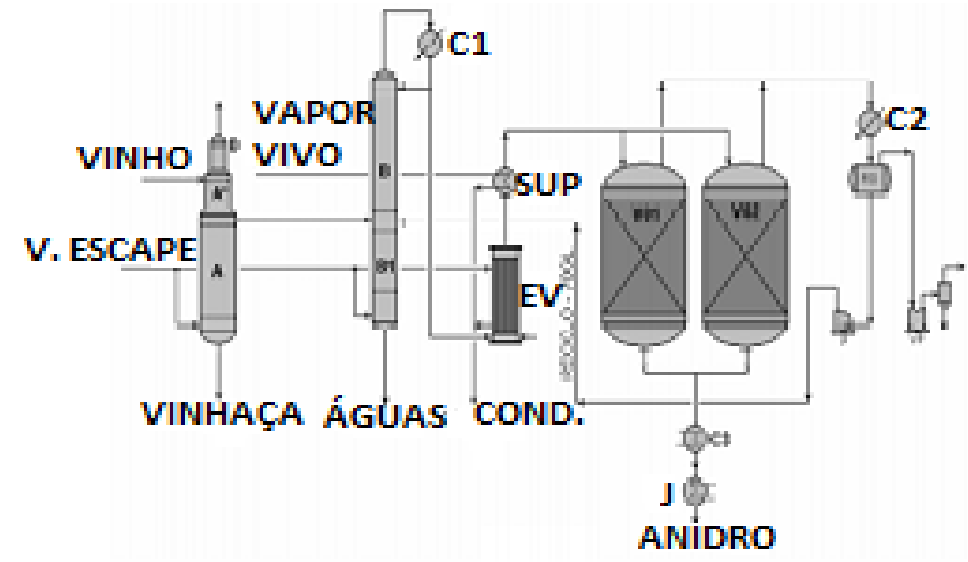

\section{RESULTADOS E DISCUSSÃO}

Na Tabela 1, são indicados os parâmetros normativos e os resultados obtidos realizados em um laboratório de uma usina sucroalcooleira do álcool hidratado. Na Tabela 2, são indicados os parâmetros normativos e os resultados obtidos realizados em um laboratório de uma usina sucroalcooleira do álcool anidro. 


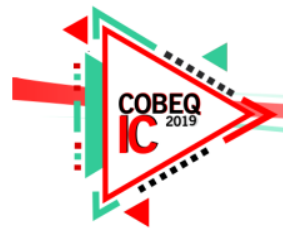

Tabela 1 - Especificação e resultados obtidos do álcool hidratado.

\begin{tabular}{|l|c|c|c|c|}
\hline \multicolumn{5}{|c|}{ Álcool Hidratado } \\
\hline \multicolumn{1}{|c|}{ Característica } & Método & Especificação & Resultado & Unidade \\
\hline Cor & VISUAL & NOTA (1) & SAC & \\
\hline Aspecto & VS1000(A) & NOTA (2) & L.I.I. & \\
\hline Condutividade & ABNT 10547 & $\leq 300$ & 69 & $\mu \mathrm{S} / \mathrm{m}$ \\
\hline Massa Específica $20^{\circ} \mathrm{C}$ & ABNT 5992 & NOTA (3) 805,2 a 811,2 & 809,7 & $\mathrm{~kg} / \mathrm{m}^{3}$ \\
\hline${ }^{\circ}$ INPM & ABNT 5992 & NOTA (3) 92,5 a 94,6 & 93 & $\%$ massa \\
\hline pH & ABNT 10891 & 6,0 a 8,0 & 6,8 & \\
\hline Acidez Total & ABNT/NBR 9866 & $\leq 30$ & 12 & $\mathrm{mg} / \mathrm{L}$ \\
\hline Teor de Hidrocarbonetos & ABNT/NBR 13993 & $\leq 3$ & - & $\% \mathrm{VOLUME}$ \\
\hline Teor de Ferro & ABNT/NBR 11331 & $\leq 5$ & 0,13 & $\mathrm{Mg} / \mathrm{kg}$ \\
\hline Teor de Cobre & ABNT/NBR 11331 & - & 0,04 & $\mathrm{Mg} / \mathrm{kg}$ \\
\hline Teor de Sódio & ABNT/NBR 10422 & $\leq 2$ & 0,58 & $\mathrm{Mg} / \mathrm{kg}$ \\
\hline Teor Sulfato & ABNT/NBR 12120 & $\leq 4$ & 0,65 & $\mathrm{Mg} / \mathrm{kg}$ \\
\hline Teor de Cloreto & ABNT/NBR 10895 & $\leq 1$ & 0,02 & $\mathrm{Mg} / \mathrm{kg}$ \\
\hline Teor de Enxofre & DIN EN 15485 & ANOTAR & 8,4 & $\mathrm{Mg} / \mathrm{kg}$ \\
\hline Teor de Metanol & ABNT 16041 & $\leq 0,5$ & $<0,1$ & $\% \mathrm{VOLUME}$ \\
\hline
\end{tabular}

Notas: (1) SAC: Sem adição de corantes; (2) Límpido e isento de impurezas (L.I.I.); (3) Para Etano Hidratado Carburante, certificado após transporte dutoviário ou aquaviário e no caso de produto importado, os limites passam a ser de $802,9 \mathrm{~kg} / \mathrm{m}^{3}$, para massa específica a $20^{\circ} \mathrm{C}$ e $95,4 \mathrm{GL}$ para teor alcoólico.

Tabela 2 - Especificações e resultados obtidos do álcool anidro.

\begin{tabular}{|l|c|c|c|c|}
\hline \multicolumn{5}{|c|}{ Álcool Anidro } \\
\hline \multicolumn{1}{|c|}{ Característica } & Método & Especificação & Resultado & Unidade \\
\hline Cor & VISUAL & NOTA (1) & SAC & \\
\hline Aspecto & VS1000(A) & NOTA (2) & L.I.I. & \\
\hline Condutividade & ABNT 10547 & $\leq 300$ & 31 & $\mu \mathrm{S} / \mathrm{m}$ \\
\hline Massa Específica 20 ${ }^{\circ} \mathrm{C}$ & ABNT 5992 & $\leq 791,5$ & 791 & $\mathrm{~kg} / \mathrm{m}^{3}$ \\
\hline${ }^{\circ} \mathrm{INPM}$ & ABNT 5992 & $\geq 99,3$ & 99,4 & $\%$ massa \\
\hline $\mathrm{pH}$ & ABNT 10891 & - & 4,7 & \\
\hline Acidez Total & ABNT/NBR 9866 & $\leq 30$ & 16,8 & $\mathrm{mg} / \mathrm{L}$ \\
\hline Teor de Hidrocarbonetos & ABNT/NBR 13993 & $\leq 3$ & - & $\% \mathrm{VOLUME}$ \\
\hline Teor de Ferro & ABNT/NBR 11331 & $\leq 5$ & 0,1 & $\mathrm{Mg} / \mathrm{kg}$ \\
\hline Teor de Cobre & ABNT/NBR 11331 & $\leq 0,07$ & 0,02 & $\mathrm{Mg} / \mathrm{kg}$ \\
\hline Teor de Sódio & ABNT/NBR 10422 & $\leq 2$ & 0,14 & $\mathrm{Mg} / \mathrm{kg}$ \\
\hline Teor Sulfato & ABNT/NBR 10894 & $\leq 4$ & 0,04 & $\mathrm{Mg} / \mathrm{kg}$ \\
\hline Teor de Cloreto & ABNT/NBR 10895 & $\leq 1$ & 0,29 & $\mathrm{Mg} / \mathrm{kg}$ \\
\hline Teor de Enxofre & DIN EN 15485 & ANOTAR & 9 & $\mathrm{Mg} / \mathrm{kg}$ \\
\hline Teor de Metanol & ABNT 16041 (3) & $\leq 0,5$ & $<0,1$ & $\% \mathrm{VOLUME}$ \\
\hline
\end{tabular}

Notas: (1) SAC: SEM ADIÇÃO DE CORANTES; (2) Límpido e isento de impurezas (L.I.I.); (3) Método que identifica a presença de metanol com base na Norma ISSO 1388-8 (parte 7). A identificação do metanol por meio dessa análise qualitativa deve ser confirmada pelo método ABNT NBR 16041 quando o resultado do teor de metanol for não-conforme. 


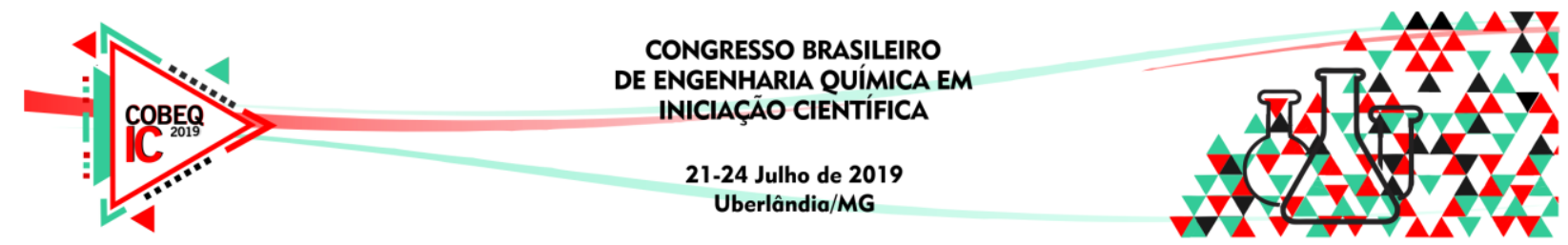

As peneiras moleculares são mais eficientes por trazer uma redução considerável no consumo de energia, baixo consumo de água de resfriamento e vapor, produção de etanol de alta qualidade (sem traços de desidratante), e aceitabilidade internacional do etanol, porque é ecologicamente correto. No Brasil, ainda existem muitas usinas utilizando a desidratação por destilação azeotrópica e extrativa apenas porque é um processo tradicional. Porém, as novas destilarias estão adotando o uso de peneiras moleculares por apresentarem vantagens que compensam seu custo mais elevado (MARQUINI, 2019).

A zeólita atua fisicamente na desidratação do etanol, portanto, não utiliza substâncias adicionais para realizar a purificação, e possibilita a obtenção de etanol com maior pureza. Relativo as densidades o etanol hidratado deve apresentar valores entre 805,2 a 811,2, obtevese $809,7 \mathrm{~kg} / \mathrm{m} 3$; e o etanol anidro $\leq 791,5 \mathrm{~kg} / \mathrm{m}^{3}$ obteve-se $791 \mathrm{~kg} / \mathrm{m}^{3}$; as duas densidades situam-se no intervalo normalizado. Relativo ao INPM o etanol hidratado deve apresentar valores entre 92,5 a 94,6 obtendo-se 93,0\% em massa; e o etanol anidro $\geq 99,3$ obtendo-se 99,4\% massa. As duas concentrações, também, situam-se no intervalo normalizado. Relativo ao $\mathrm{pH}$ o etanol hidratado deve apresentar valores entre 6,0 a 8,0, obtendo-se 6,8; e o etanol anidro não tem especificação de $\mathrm{pH}$ padronizada pela ABNT. Os outros parâmetros também atenderam aos padrões da ABNT.

\section{CONCLUSÕES E CONSIDERAÇÕES FINAIS}

Com a finalidade de alcançar os objetivos propostos neste estudo, após descrever todos os processos de produção de etanol anidro, foi realizada uma comparação das exigências descritas em normas da ABNT com o etanol obtido com uso de peneira molecular, onde são efetuadas especificações do etanol hidratado e do etanol anidro, com os resultados obtidos em uma usina, mostrando que todos os resultados estão dentro dos parâmetros exigidos por legislação. O etanol hidratado apesentou densidade de $809,7 \mathrm{~kg} / \mathrm{m}^{3}$; e o etanol anidro 791 $\mathrm{kg} / \mathrm{m}^{3}$. O INPM do etanol hidratado e anidro foram, respectivamente: $93,0 \%$ e 99,4\%. Todos os outros parâmetros atenderam a normalização da ABNT.

\section{REFERÊNCIAS}

SOLOMONS, G.; FRYHLE, C.; Química orgânica. 7. ed. Rio de Janeiro: LTC, p. 645, 2001.

PEREIRA, C. M. P.; HOBUSS, C. B.; MACIEL, J. M.; FERREIRA, L. R.; DEL PINO, F. B.; MESKO, M. F.; Biodiesel renovável derivado de microalgas: avanços e perspectivas tecnológicas. Química Nova, v. 35, n. 10, p. 2013-2018, 2012.

MARQUINI, M. F.; SICCHIERI, V. F.; MUSSI, G.; JW. Manual de operação. Unidade de desidratação de etanol. Agroenergia Santa Luzia ltda. 2019.

ROELOFSEN, R. P.; Properties and aplication in organics shinthesis. Delftche Uitgevers Maats Chappij: Delft. 1972. 